\title{
Is lung ultrasound the stethoscope of the new millennium? Definitely yes!
}

\author{
Roberto Copetti* \\ Emergency Department Latisana \\ General Hospital Latisana, Italy \\ ${ }^{\star}$ Corresponding author: \\ robcopet@gmail.com \\ Tel.: + 390431529328 \\ Fax.: + 390431529461
}

Received/Accepted: 2 May 2016

Key words: Lung ultrasound - Pneumonia - Children.

Children with community acquired pneumonia may present with a wide spectrum of different clinical signs and symptoms as fever, tachypnoea, breathlessness or difficulty in breathing, cough, wheeze, chest pain, tachycardia, rales, rhonchi, crackles, decreased breath sounds, low oxygen saturation. These findings, especially in infants, are highly specific and greatly increase the likelihood of pneumonia when present. However, their absence does not rule out pneumonia, and the accuracy of any individual sign or symptom is limited (1).

According to current guidelines, chest radiography should not be routinely performed in an ambulatory setting, and diagnosis is therefore frequently committed to clinical evaluation alone (2). Recently, current evidences have been included in a meta-analysis which confirmed the high accuracy of lung ultrasound in the diagnosis of pneumonia in children (3).
Lovrenski and colleagues (4), compared lung ultrasound with auscultation findings in children with clinical suspected pneumonia and demonstrated that lung ultrasound showed positive findings in more hemithoraces than auscultation. These data are very interesting and impose a serious reflection about the objective limits of classic semeiotics. The stethoscope is the symbol of doctors, and palpation, percussion and auscultation represented for nearly two centuries the art of the physical examination. The doctor who was exploring the patient's body in the nineteenth century and the first decades of the twentieth century, probably thought to have the sensibility of an artist, and perhaps the ear of a musician. This semeiotics has been the essence of the so called "medical art". The explosive growth of medical technology in the last fifty years has limited the use of the senses for patients' examination and has stripped its limits.

Lovrenski and colleagues (4) demonstrated that in about $95 \%$ of auscultatary examinations it is not possible to determine the presence of the consolidation of the lung parenchyma with a cranio-caudal diameter less than $30 \mathrm{~mm}$. These measures are often found in the early stage of pneumonia. This means that we need to fill the gap between semeiotics and its limits. Another interesting point of the paper of Lovrenski and colleagues (4), is the suggestion to perform 
lung examination with a combined transabdominal and trans-thoracic approach. In one child trans-hepatic examination of the lung base detected a consolidation not visible only with the trans-thoracic approach. Doubtless this recommendation might increase the sensitivity of lung ultrasound.

Ultrasound is a radiation free technique and this is an undoubted advantage in the pediatric population in which serious concerns about radiation exposure have been raised. It is high time to consider ultrasound the best stethoscope in our hands. It is high time to include lung ultrasound in the international guidelines and in our clinical practice.

The basic form of the stethoscope was invented by the French physician René-Théophile-Hyacinthe Laënnec who published a description of the instrument in 1819. In 1821 Laënnec's book was translated into English by sir Johan Forbes that in the preface wrote: "... notwithstanding its value, I am extremely doubtful; because its beneficial application requires much time, and gives a good deal of trouble both to the patient and the practitioner ..." (5).

It makes me smile to think that today there is still someone who think the same about the using of lung ultrasound in the routinely clinical practice. It's time to change!

Conflict of interest: The author declares that he has no conflict of interest.

\section{References}

1. Lynch T1, Platt R, Gouin S, Larson C, Patenaude Y. Can we predict which children with clinically suspected pneumonia will have the presence of focal infiltrates on chest radiographs? Pediatrics. 2004;113(3 Pt 1):e186-9.

2. Harris M, Clark J, Coote N, Fletcher P, Harnden A, McKean M, Thomson A; British Thoracic Society Standards of Care Committee. British Thoracic Society guidelines for the management of community acquired pneumonia in children: update 2011. Thorax. 2011;66 Suppl 2:ii1-23.

3. Pereda MA, Chavez MA, Hooper-Miele CC, Gilman RH, Steinhoff MC, Ellington LE, et al. Lung ultrasound for the diagnosis of pneumonia in children: a meta-analysis. Pediatrics. 2015;135(4):71422.

4. Lovrenski J, Slobodanka Petrović S, Balj-Barbir S, Jokić R, Vilotijević-Dautović G. Stethoscope vs. ultrasound probe - which is more reliable in children with suspected pneumonia? Acta Med Acad. 2016;45(1):39-50.

5. Forbes J. A treatise on diseases of the chest in which they are described according to their anatomical characters, and there diagnosis established on a new principle by means of acoustic instruments. London: T \& G Underwood. 1821. 